\title{
Un acercamiento al arte rupestre en cuatro municipios de la RACCN, Nicaragua
}

\author{
Arql. Kevin González Hodgson \\ Máster en Métodos de Investigación Científica \\ Docente-Investigador del Centro Arqueológico de Documentación e Investigación (CADI) \\ UNAN-Managua, Facultad de Humanidades y Ciencias Jurídicas \\ hodgsonk27@hotmail.com / chorotega310885@gmail.com
}

Fecha de recepción: 15 de octubre, 2019 / Fecha de aceptación: 06 de noviembre, 2019 https://doi.org/10.5377/torreon.v8i21.8852

Palabras clave: arte rupestre, aproximación interpretativa, cotidianidad, iconografía, pictografía, Región Autónoma de la Costa Caribe Norte de Nicaragua, testimonio.

\section{RESUMEN}

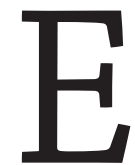

sta investigación presenta una clasificación estilística de 45 representaciones gráficas rupestres, (petrograbados y pictografías), localizados en cuatro municipios de la Región Autónoma de la Costa Caribe Norte de Nicaragua resultado de varias etapas de investigación. El objetivo principal de este estudio consistió en analizar los motivos rupestres a través, de un análisis iconográfico que, además, implicó determinar el contexto histórico-cultural de elaboración y el significado aproximado de las características icónicas identificadas en los ejemplares seleccionados. De acuerdo a los resultados obtenidos de la descripción iconográfica y tomando en cuenta importantes variables en su configuración como las técnicas de elaboración y las características de las rocas sobre las que se plasmaron las representaciones son indicadores sustanciales para decir, que los ejemplares estudiados fueron elaborados sobre la base de diversos grados de especificidad técnica y estilística por tanto, el grupo cultural que dio origen a este tipo de manifestación gráfico rupestre dejó testimonio de complejas escrituras que permitieron a través de las imágenes representar su realidad, es decir, su cotidianidad y entorno con un entramado simbólico muy importante. 


\section{ANTECEDENTES}

El presente estudio es resultado de varias etapas de investigación, que en principio surge a raíz de mi tesis de licenciatura denominada "Arqueología en la RAAN: una aproximación al pasado", presentada en la Universidad Nacional Autónoma de Nicaragua en 2009. Desde entonces, por varios años junto con otro colega, he publicado otro artículo ${ }^{1}$ sobre el cual se retoman datos y que son presentados en esta ocasión. A los propósitos de este estudio, el objetivo principal consistió en analizar los motivos rupestres a través de un análisis iconográfico que, además, implicó determinar el contexto histórico-cultural de elaboración y el significado aproximado de las características icónicas descritas.

El conjunto muestral procede de cuatro municipios de la Región Autónoma de la Costa Caribe Norte de Nicaragua, concretamente en los territorios de Kirwas ${ }^{2}$, San Alberto ${ }^{3}$, Santa Fe y San Jerónimo en las riberas del río Coco correspondiente al municipio de Waspán, zona fronteriza con el país vecino de Honduras; Tungla y Buena Vista en el municipio de Prinzapolka, la comunidad de Panamá en el municipio minero de Bonanza y La Florida en el municipio de Rosita, territorios habitados ancestralmente por Miskitos y Mayangnas.
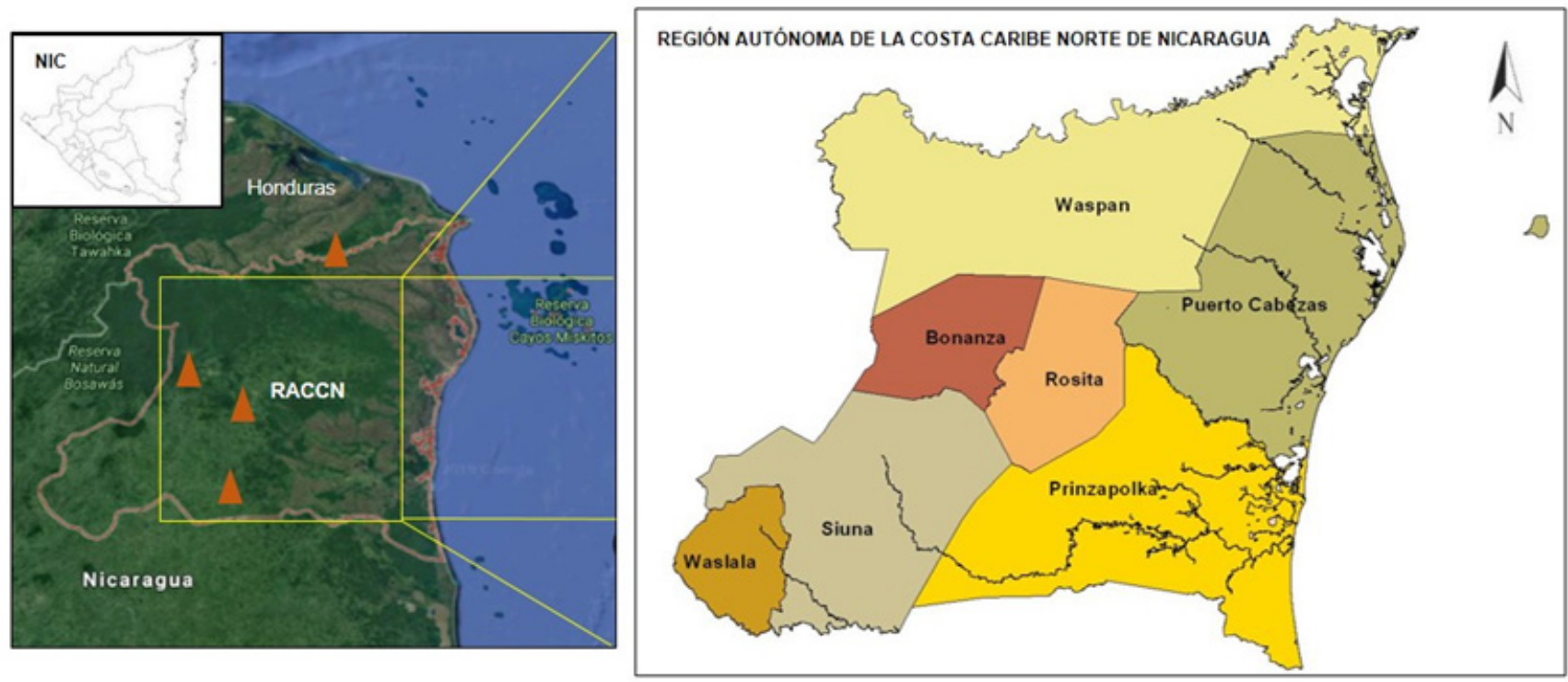

Esquema de ubicación de los lugares donde proviene la muestra de estudio. Fuente: googlearth/adaptado por el autor.

A propósito de los petrograbados localizados en los municipios de Rosita y Bonanza, corresponden a sitios arqueológicos con relieve accidentado; por su parte la muestra procedente 1. En el marco del proyecto Fondo de Investigaciones para la Revitalización Cultural y Desarrollo Productivo Creativo de la Costa Caribe de Nicaragua-RAAN, MDGF1827 (Partnership BICU-UNESCO), se realizó la investigación Inventario de Sitios Arqueológicos en el Municipio de Rosita y su posterior publicación. Para más información consultar https://www.lamjol.info/index.php/WANI/article/download/884/697

2. Posiblemente el término se haya castellanizado sin embargo en el diccionario de toponimias indígenas aparece como Kiwas, caño que desemboca en el río Coco, aguas debajo de Kum. Caño cabecero del río Yulu Tigni, de la cuenca del Layasiksa, (Incer, 1985, p.112).

3. Tanto Kirwas y San Alberto son sitios con arte rupestre que no han sido documentados arqueológicamente, no obstante, por la naturaleza de la evidencia existente en el lugar se incorpora los datos de éste al análisis. 
de las localidades de Waspán y Prinzapolka ${ }^{4}$ están situados en zonas rivereños es decir, entre los raudales en este caso por el río más extenso de Centroamérica el Coco y por otra parte por el río Prinzapolka otro importante río en la región del caribe nicaragüense.

Por ahora, la historia antigua de la Costa Caribe Norte del país es muy poca conocida, lo que ha conducido a que sea objeto de mucha especulación en cuanto a su riqueza arqueológica; en efecto, son pocos los historiadores y arqueólogos que interesados en el pasado de nuestro país han dirigido sus esfuerzos intelectuales hacia esta vasta región pluricultural y multilingüe por varias razones desde la escasez de estudios o literatura afín, lo económico o bien por las condiciones climáticas que dificultan el acceso hacia sitios de interés arqueológico, por lo tanto, los habitantes de estas regiones se han visto durante largo tiempo relegados en el estudio histórico de sus raíces prehispánicas. Hasta hace poco, antes del siglo pasado, la única información proveniente de esta zona consistía en pesquisa de algunos informes breves y descriptivos, además de aficionados locales quienes reportaban sobre la existencia de tiestos cerámicos en superficie y grabados en piedra.

Al respecto, hurgando en la poca literatura a mano están algunos estudios etnohistóricos y arqueológicos que dan cuenta sobre el pasado en el caribe Norte, entre los que se reporta evidencia material referido, además de hachas de piedra, estructuras monticulares y metates, "inscripciones rupestres, en diferentes sitios sobre el río Coco como Wirapani, Waspuk, Kirwas, arriba de Raití, en Kumkum Mawan y en Tawit” (Conzemius, 2004, p.75). Contexto análogo es la "cuenca de Uli Was donde se han observado petroglifos que bien pueden tener unos 2500 años de antigüedad y cerámica gruesa de color café oscuro, muy tiznada por el uso, que parece haber servido para la preparación de comidas en las festividades comunales así mismo vasijas similares de gran tamaño utilizada para los entierros funerarios" (Hurtado de Mendoza, 2000). Otro referente de singular importancia son los datos que se ofrece en el libro "Mayangna, apuntes sobre la historia de los indígenas Sumus en Centroamérica" de (Houwald, 2003:269), en él se brindan pistas sobre la identificación de un tipo de cerámica en la comunidad de Santa Fe, río Coco determinado como "Mokó Plain". Por otro lado y con pocos días de prospección en el año 2007 y 2008 fue posible constatar que no solo existían algunos de los sitios revelados por los investigadores citados sino que también se encontraron evidencias materiales de otro tipo muy singulares, es decir, en esa oportunidad los resultados obtenidos durante dos jornadas de campo permitieron documentar un total de 20 sitios arqueológicos clasificados en relación al tipo de evidencia encontrada entre las que destacan: sitios con petroglifos, con petroglifos y material en superficie, con material en superficie y estructuras monticulares y cuevas, distribuidos en los municipios de Waspán,

4. "De Prinsu, una de las tribus Sumu; pohka, el monte: la selva de los Prinzus". Ibíd., p. 78.

5. La tipología cerámica fue establecida por el Dr. Wolfgang Haberland a solicitud de Houwald; el arqueólogo sospecha que la tipología analizada corresponde a una cerámica Sumu histórica. 
Rosita, Prinzapolka y Bonanza (González Hodgson \& Taylor, 2009, p.117) ${ }^{6}$, además, de la documentación y registro en el municipio de Rosita de 17 sitios arqueológicos distribuidos éstos entre estructuras monticulares (2), material en superficie (12), petroglifos (3) y estatuilla (1), de acuerdo a lo documentado por los autores González Hodgson y Taylor, (2012).

\section{MATERIAL Y MÉTODO}

El procedimiento comenzó con; 1) búsqueda documental y selección de los 45 ejemplares; la muestra fue seleccionada a partir, de fotografías realizadas directamente en los sitios al igual de tesis, informes, libros y archivos fotográficos cedidos por el Centro Cultural TININISKA ${ }^{7}$ y de aficionados locales ${ }^{8}$ que permitieron el proceso de redibujo con la salvedad de que no se pudieron establecer secuencias a partir de técnicas de manufacturas aplicadas. 2) elaboración de ficha técnica de registro de cada uno de los petrograbados que permitió la caracterización inicial de la muestra. 3) identificación y clasificación de los rasgos estéticos recurriendo al análisis iconográfico entendido como la rama de la historia del arte que se ocupa del asunto o significación de las obras de arte en contraposición de su forma (Panofsky, 1979, p.45) ${ }^{9}$, tomando en cuenta tres niveles de interpretación: pre-iconográfico o significación primaria-natural de las formas, iconográfico o significación secundaria-asociación de formas y el nivel iconológico o significado intrínseco de contenido de la forma.

\section{SECUENCIA}

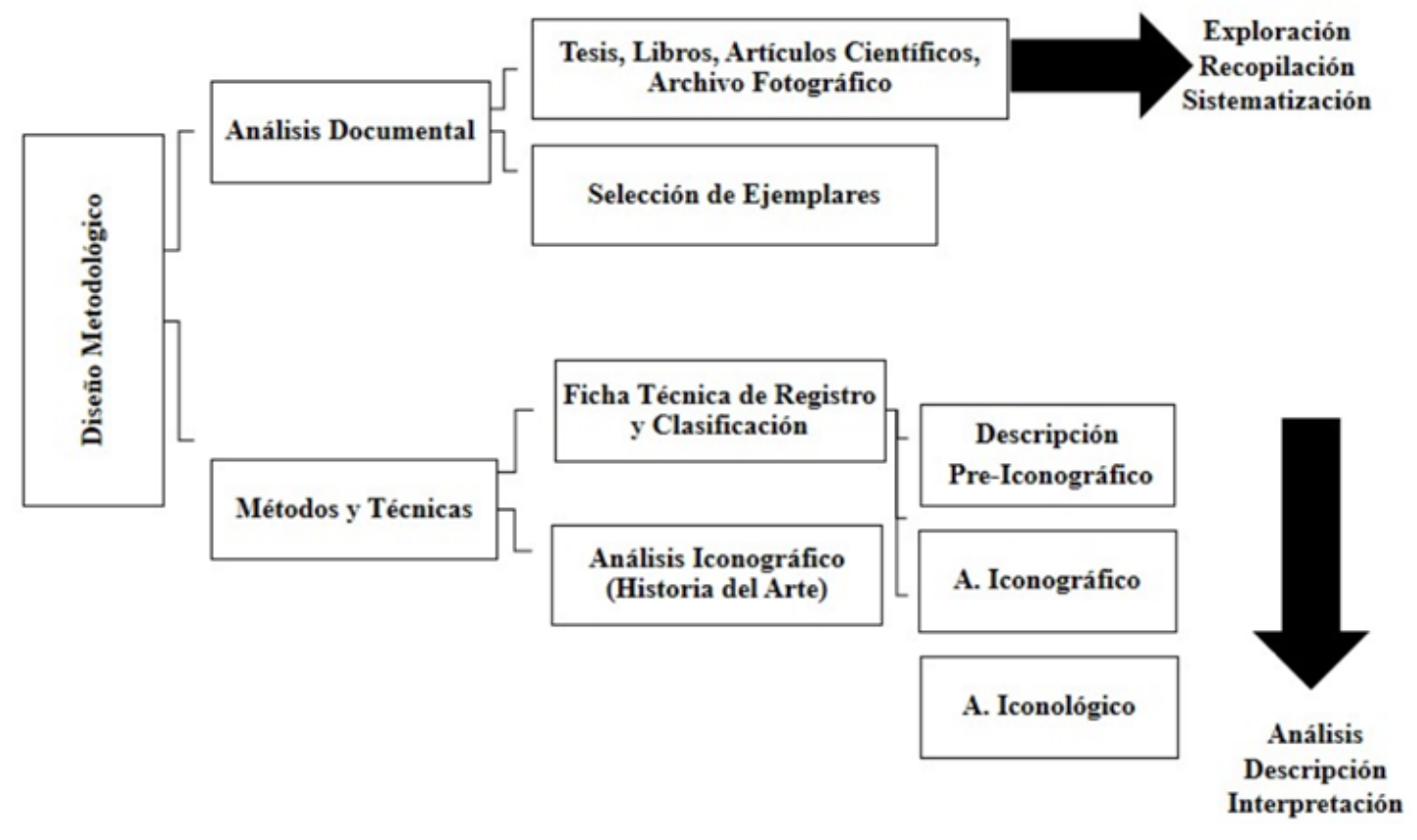

Síntesis del procedimiento realizado en el proceso de análisis iconográfico. Fuente: El Autor.

6. Un total de 228 piezas arqueológicas entre ellos cerámicos (180) y líticos (48).

7. Tiene su sede en la ciudad de Puerto Cabezas encargado del rescate cultural de las étnicas Miskitu y Mayangna de la Costa Caribe de Nicaragua.

8. Entre ellas está Mariela Kitler habitante del municipio de Waspán.

9. Su análisis se basa en la subjetividad de la percepción. 


\section{Descripción de las representaciones gráficas}

Los resultados obtenidos permiten diferenciar a groso modo dos tipos de manifestaciones rupestres entre ellos petrograbados (uso de la técnica de talla) y pictografías o pinturas rupestres (aplicación de pigmentos en las superficies rocosas); en un primer nivel de clasificación o análisis pre-iconográfico y de acuerdo a las características de los diseños se determinaron dos grupos de elementos visuales, el primero de ellos, representaciones abstractivas ${ }^{10}$ que pertenecen en su mayoría a motivos geométricos (20), seguido de elementos antropomorfos (13) y luego de representaciones zoomorfos con (12); los grabados con características geométricas se presentan en una variedad de diseños por ejemplo las espirales doble divergente (43\%) y espirales con más de tres vueltas representan un (52\%).

\section{Clasificación morfológica de los diseños rupestres}

= Antropomorfos =Zoomorfos $=$ Geométricos

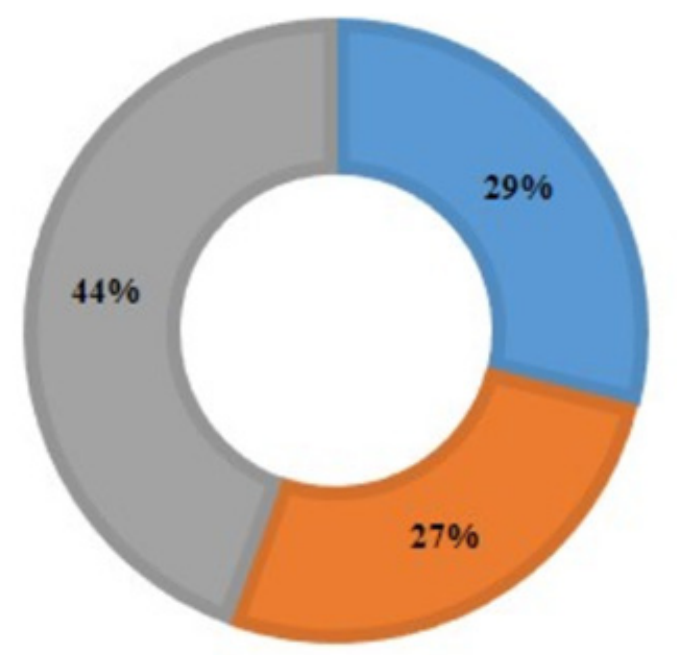

Gráfico 1. Porcentaje de las manifestaciones rupestres identificadas según forma. Fuente: El Autor.

En cuanto a las variantes identificadas en el uso de líneas, esta se destaca por la frecuente utilización de la curva (15\%) y la diagonal (15\%), además, de puntos y círculos (14\%), seguido del uso de recta (7\%), curva y vertical (7\%), vertical o diagonal (7\%), sinuosidad o zigzag (7\%), vertical y horizontal (7\%), línea y círculo (7\%), con oquedad (7\%) y conjunto de puntos y círculos (7\%).

10. Determinado por motivos abstractos (líneas, puntos y otros por su composición estructural). 


\section{Variabilidad en el uso de líneas}

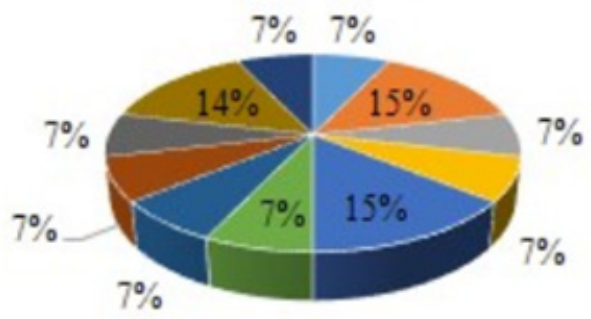

- Recta

- Curva y vertical

- Diagonal

- Vertical/horizontal

- Con oquedad
- Curva

- Vertical/diagonal

- Sinuosidad/zigzag

- Línea y círculo

- Puntos y círculos

- Cojunto de puntos y círculos

Gráfico 2. Frecuencia en el uso de la técnica de líneas en los diseños. Fuente: El Autor.

Los datos sugieren que los motivos geométricos tienen rasgos bastante complejos e imaginativos, al menos así lo deja entrever uno de los ejemplares analizados en este caso definido como elemento soliforme asociado eventualmente a representaciones astronómicas ya sea simplemente como reflejo de señalización del astro (sol) o bien, por el hecho de algún acontecimiento más específico como eclipses y otros vinculados a la categoría sugerida.

Por su parte, los rasgos representativos realistas/naturalistas ${ }^{11}$ corresponden tanto a rostros humanos y cuerpos enteros con características específicas entre ellas, se determinó mayor porcentaje de elementos afines a rostros/caras con contorno en un (39\%), además, un (37\%) de la muestra corresponde a rostros/caras en forma triangular observando así mismo un (9\%) en los diseños con semi-contorno, semi-circular (9\%) y en los diseños indeterminados con un (9\%). Luego están en el orden los diseños ovalados (4\%) y diseños cuadrados (4\%).

11. Integrado por motivos antropomorfos y zoomorfos tanto rostros y extremidades superiores e inferiores. 


\section{Características morfologicas de Rostros/Caras/Cuerpos identificados}

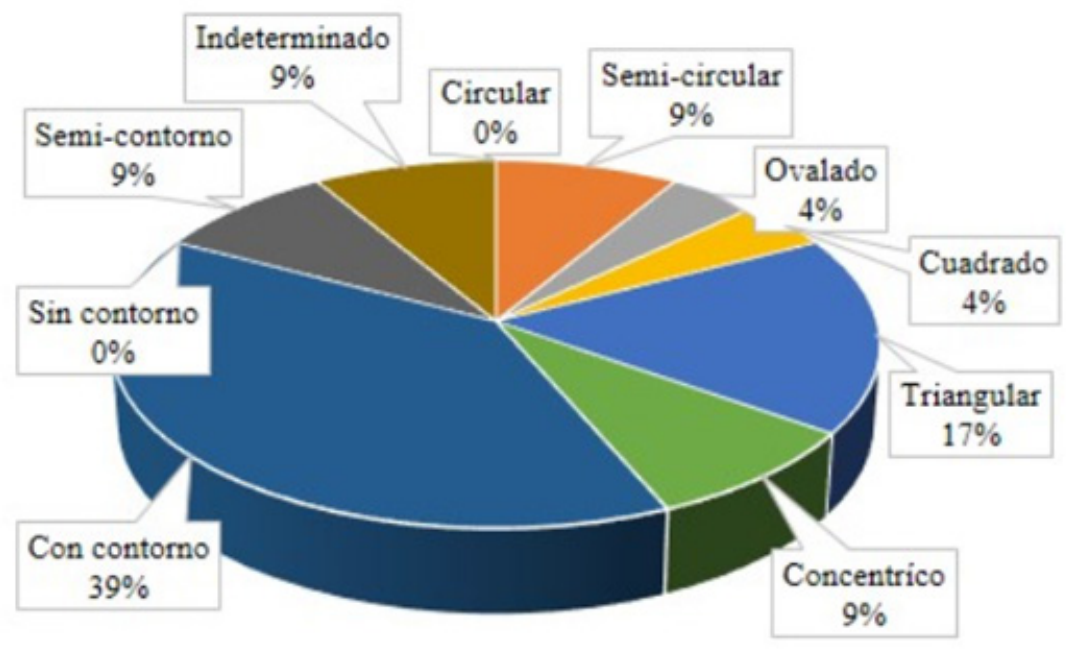

- Circular

- Semi-circular

- Ovalado

- Cuadrado

- Triangular

- Concentrico

- Con contorno

- Sin contorno

- Semi-contomo

- Indeterminado

Gráfico 3. Frecuencia de las características identificadas en rostros, cara y cuerpos analizados. Fuente: El Autor.

A su vez los rasgos identificados en los elementos anteriores se caracterizan por presentar mayormente ojos ovalados (28\%) y ojos circulares (20\%); en tanto hay predominio de boca lineal (16\%) seguido en el orden de boca ovalada (12\%) al igual que boca circular (12\%) y finalmente un (4\%) responde a aquellos diseños con elementos faciales visibles. Sobre la base anterior y tratando de identificar aspectos más en detalle sobre características o atractores faciales hay un (36\%) de los motivos en movimiento, (29\%) en estado de asombro, un (21\%) en posición contemplativo y $(14 \%)$ con característica o en estado de animación.

Con respecto al análisis de los elementos zoomorfos, estos reflejan motivos predominantes con diseños indeterminados (37\%), seguido de motivos con características de felino (18\%), luego en el orden están los motivos con características de monos (9\%), aves (9\%), tortuga (9\%), peces (9\%) y reptiles (9\%). 


\section{Fauna identificado y clasificado}

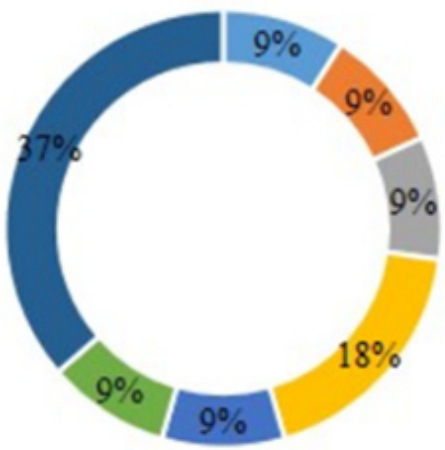

" Monos " Aves | Peces " Felino | Tortuga | Reptil " Indeterminado

Gráfico 4. Graficación estadística de las características de los motivos faunísticos identificados. Fuente: El Autor.

En la mayoría de los casos la materia prima sobre la que fueron elaboradas las grafías corresponden a rocas basálticas de tamaños variables de la provincia geológica de la Costa Atlántica aflorados naturalmente en la zona y que, de acuerdo, a las observaciones de distribución de los motivos en su totalidad fueron tallados tanto en el centro de la roca y costados de estos.

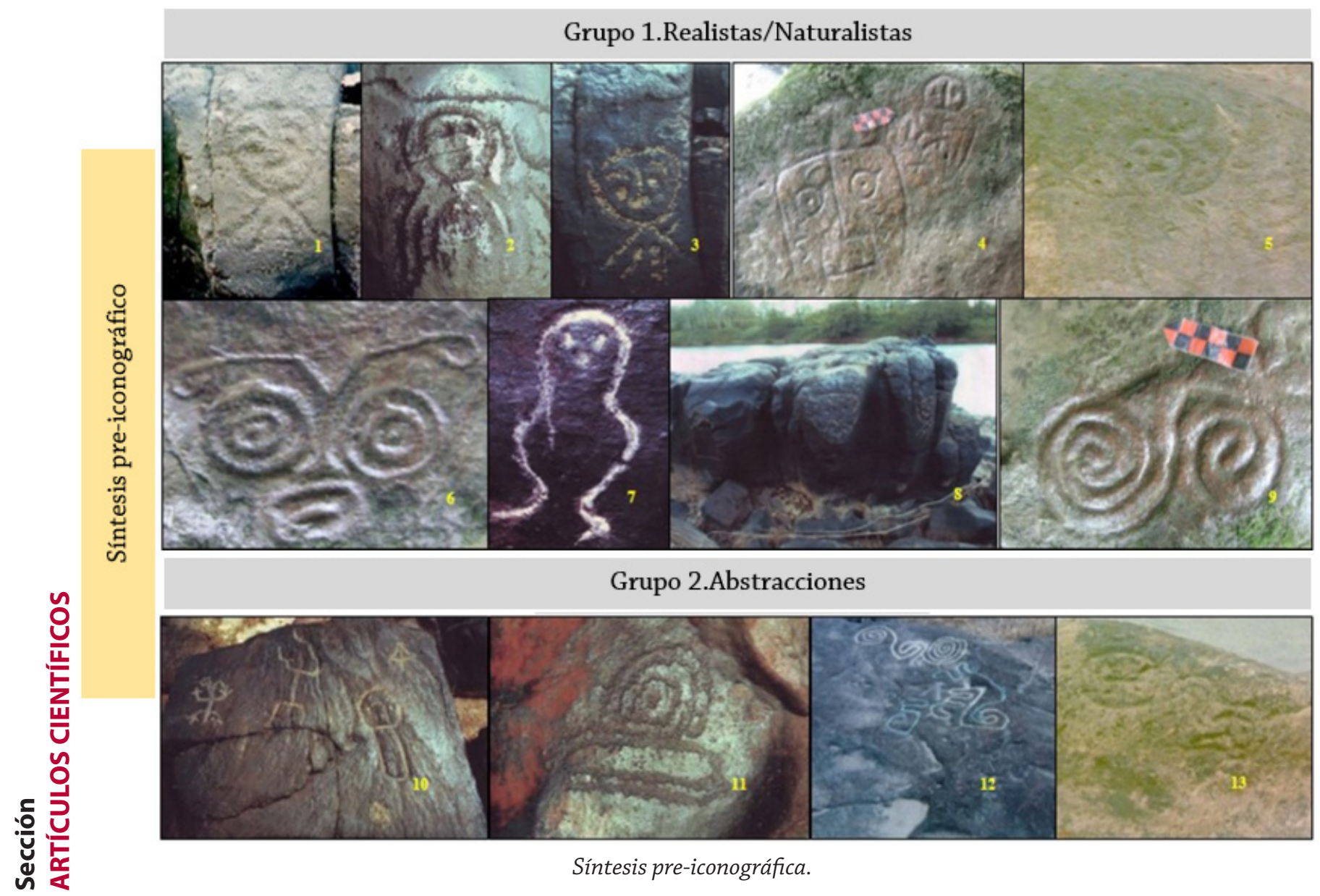


La técnica básica de manufactura identificada es el de bajo relieve en la mayoría de la muestra pero también, se aplicó la técnica de trazos ${ }^{12}$ como así lo deja entrever al menos 7 inscripciones procedentes del territorio de Santa Fe, cuya superficie rocosa evidencian pigmentación de color amarillento/rojizo y blanco.

\section{¿Iconológicamente que significados transmiten los motivos analizados?}

$\mathrm{Si}$ bien es cierto que este estudio recurre metodológicamente a los planteamientos de la historia del arte, también, por las características del objeto de estudio es indispensable retomar el concepto de estilo que puede entenderse como "the particularity of action and meaning that is built up within an historical context" (Hodder, 1985:10), tal como lo sugiere el análisis iconológico realizado en esta ocasión referido a las unidades realistas y abstractas que expresan a su vez subcategorías importantes de acción y significación construidos dentro de un contexto específico humano, animal, geométrico y eventualmente relacionado a sucesos geométricos definidos morfológicamente por el uso frecuente de líneas y que sintetiza una abstracción pensativa de parte del creador de los motivos por cuanto ese conjunto de normas determinadas por un sistema de saber-poder definen una forma particular de inscripción gráfica, transformándose ésta en la concreción material de tal sistema (Foucault, 1992). Así, por ejemplo, con frecuencia en otras latitudes del mundo el elemento geométrico atiende a aspectos como delimitación de áreas, volúmenes (ancho, alto, profundidad o simples formas), de tal manera que la línea que aparece (en la imagen 10 superior), parece determinar una especie de flecha con un alto grado de trabajo y orientación cognitiva de acuerdo a su característica morfológica.

Otro motivo importante es la línea recta (imagen 14), que por sus rasgos parece estar vinculado a extensión o punto de separación y que eventualmente el motivo analizado por estar situado en los raudales del río Coco parece despertar algún interés por parte de sus creadores por graficar formas relativos al recurso hídrico inmediato, es decir, al analizar el estilo como un constructo determinado por un sistema de saber-poder, va implícito el hecho de diferentes formas de estar en el mundo, y por tanto de entenderlo, generan expresiones rupestres disímiles en sus normas constructivas (Troncoso, 2003, p.212). En tanto la línea vertical o diagonal atiende figuradamente a un estado de calidez, firmeza o bien la posibilidad de movimiento con tendencia a crecer, pero no sólo a lo positivo, pero también, tiene un significado inverso (descendencia, tragedia, amenaza).

12. Este tipo de representación gráfica sobre piedra por lo general, además, de realizar trazos en la superficie rocosa se aplicaban sustancias minerales, sangre de animales o sustancias vegetales que servían de colorantes. 

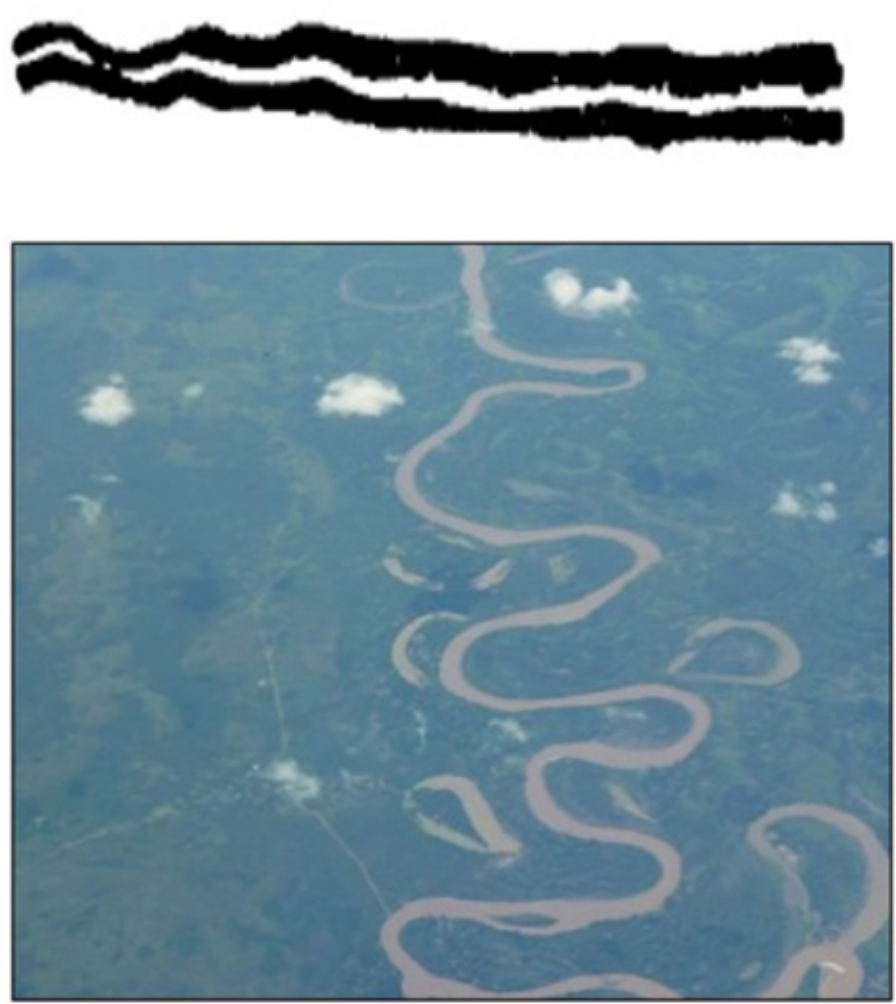

Nótese en la parte superior un petroglifo documentado en los raudales del río Coco por Edward Conzemius, 1984:104 en su libro "Estudio Etnográfico sobre los Indios Miskitos y Sumus de Honduras y Nicaragua"; Abajo fotografía aérea del mismo. Fuente: google.com

Con respecto a la línea vertical y curva como geometría cabe agregar un último comentario referido a la (imagen10) localizado en la comunidad de Santa Fe, si bien es cierto que la mayor parte de estas iconografías han sido documentadas como parte de la categoría y subcategoría abstracta, el panel ofrece la perspectiva singular y bastante sugerente por cuanto se observa en el extremo izquierdo de la roca una especie de ideograma zoomorfo en movimiento y en el centro del mismo un elemento antropomorfo con pies semi-flexionados, una línea recta en el centro que define la silueta del cuerpo, una especie de curvatura que define brazos con lo particular que el elemento antropomorfo sugerido parece tener figurativamente en su brazo derecho una punta de proyectil; no obstante este tipo de interpretaciones son apenas aproximaciones preliminares pero a decir verdad, "solo cuando planteamos hipótesis acerca de los significados subjetivos presentes en la mente de una comunidad humana del pasado podemos empezar a hacer arqueología" (Hodder, 1994, p.95).

Por su parte, los grabados denominados espirales son "representaciones simbólicas del agua" (Manzanilla, 2006, p.124), morfológicamente es una curva trazada por un punto en movimiento y este gira alrededor de un punto fijo eventualmente ligado a movimientos de rotación y traslación o proceso cíclico, crecimiento o expansión; en el análisis se identificaron dos tipos de espirales simples y aquellas que alcanzaron al menos más de 2 vueltas o doble 
divergente o hiperbólico ${ }^{13}$, término planteado por el matemático Arquímedes Siracusa (287 a.C. - 212 a.C.) que de acuerdo a diversas latitudes, cultura y teóricos el significado varía pero sin perder su esencia de "ciclo" y simbólicamente ligado a "nacer-morir-renacer", además, de atender al concepto de crecimiento, expansión y energía cósmica, dependiendo de la cultura en la cual se ha usado. Para los antiguos habitantes de Irlanda, la espiral fue utilizada para representar el Sol (https://matematicasiesoja.files.wordpress.com/2013/10/espiralesarte.pdf)
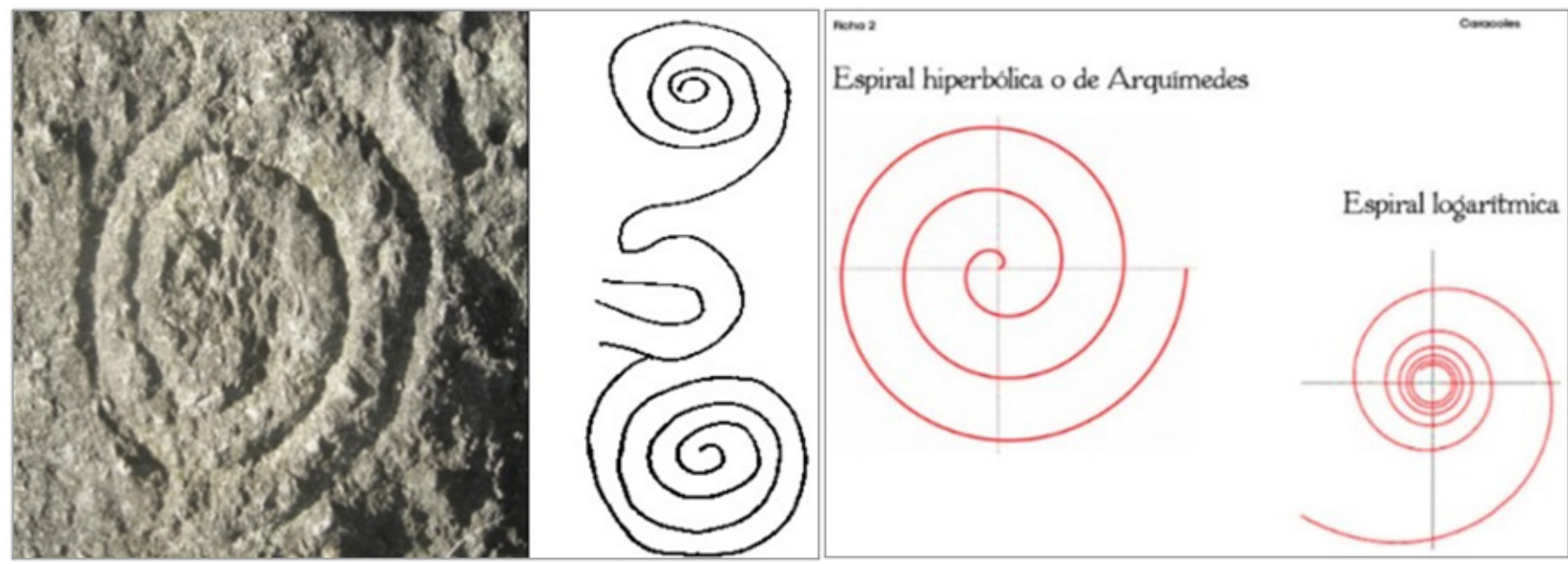

Espiral simple documentado en el municipio de Rosita; espiral doble o divergente localizado en San Jerónimo e ilustración propuesta por el matemático Arquímedes que permite interpretar a partir de elementos geométricos los grabados analizados en esta oportunidad. Fuente: González y Taylor, 2009/google.

Adicionalmente, siempre sobre la base de lo geométrico las líneas con su variante en forma de zigzag, manifiesta ondulaciones y su presencia como parte del arte rupestre estudiado en los territorios de Santa Fe y San Alberto en el río Coco, parecen representar ya sea una admiración a los rompientes del río por la sinuosidad del motivo o bien veneración por representar gráficamente el rayo que por lo general este es elaborado siguiendo un esquema en forma de zigzag es decir, ángulos entrantes y salientes que denotan movimiento, en concreto las líneas zig-zag representaban la lluvia, el agua, el río o la serpiente por su parentesco con la línea ondulada (Golan, 1994, p.84 citado por Kolpakova, 2009, p.96). En tanto, el punto dentro del círculo o llámese círculo concéntrico no deja de ser abstracto y sobre él hay un sinnúmero de interpretaciones al respecto, entre ellas parece revelar un culto al sol, otros que indican que el punto es el (sol) y el círculo el (universo) o vinculado a un símbolo de poder fecundante.

13. Además, era usado para representar los equinoccios cuando el día y la noche tienen la misma duración. 


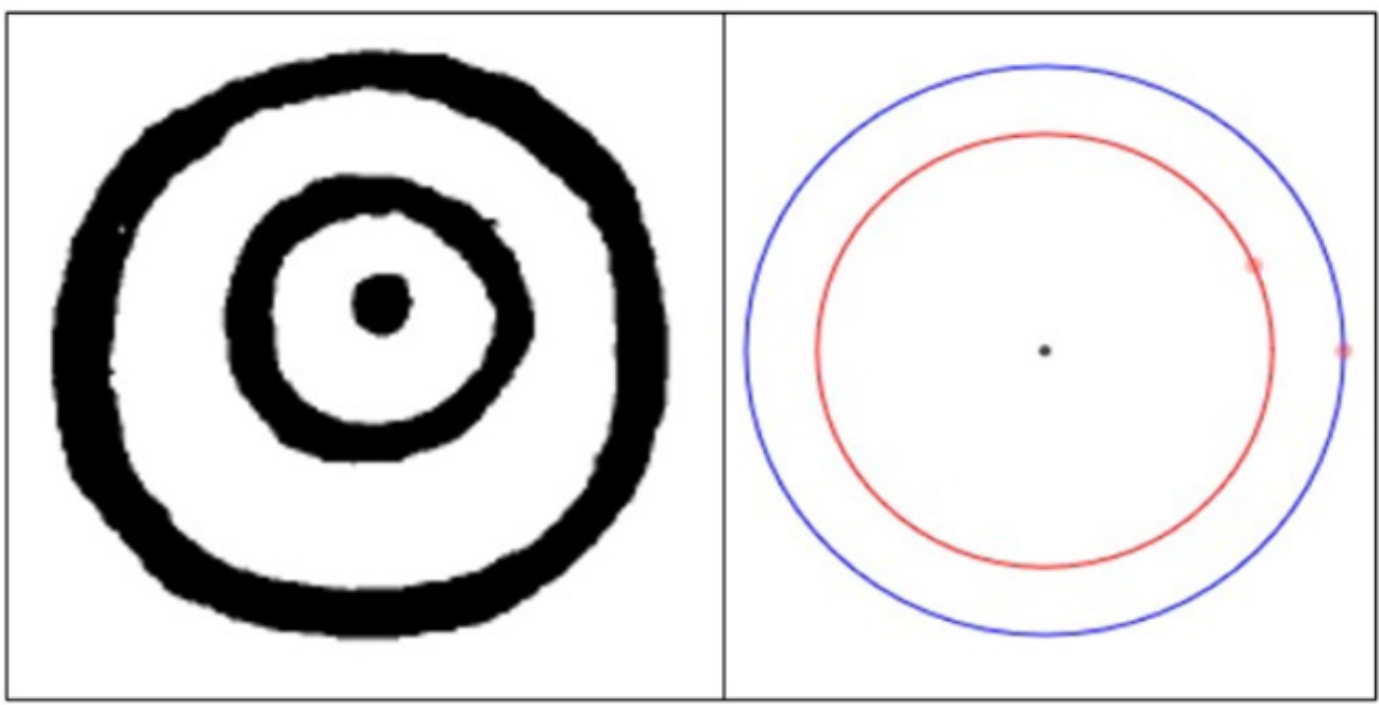

Petroglifo documentado en los raudales del río Coco por Edward Conzemius, 1984:104 en su libro "Estudio Etnográfico sobre los Indios Miskitos y Sumus de Honduras y Nicaragua" e ilustración que orienta una alineación geométrica del motivo. Fuente: google.com

Con respecto, a lo anterior y la posibilidad de realizar un tipo de paralelismo etnográfico desde la cosmogonía de los indios Sumus la concepción del sol y la luna como hermanos está difundida en el área; muchos pueblos chibchas la presentan (Constenla, 1990, p.70), de hecho en mitos y leyendas de esta cultura, el número dos se presenta como el número mágico entre los Sumus: dos son los creadores, dos son los Ditalyang (jefes, guías), dos hermanos provocaron la gran inundación, en dos cerros, el Yaluk y Aluk se realizaban los ritos de iniciación (...), igualmente elementos astronómicos acontecidos fueron representados en piedra, quizás a ello se deba a que en el "río Patuka, que los sumos llaman Matuka, los eclipses de la luna causaban antes una gran sensación en el ánimo de la gente.

Al iniciarse el fenómeno, chicos y grandes se levantaban, encendían grandes hogueras y hacían ruidosas manifestaciones tocando tambores, golpeando latas o cualquier otro objeto, para conjurar las posibles desgracias que se cernían sobre la tribu. Venían en este acontecimiento una especie de lucha entre el bien y el mal, entre la luz y las tinieblas y otros creían que un tigre estaba comiéndose a la luna. (Arguedas, 1992, p.55-56)

Algo similar sucede con la (imagen 21) definido como soliforme (Manzanilla, 2018, p.41), por lo visto iconográficamente, hace referencia a dos cuerpos que tienen por tanto el mismo centro que el otro, al igual que su eje u origen. Especial atención merece la (imagen 22), que parece tener algún grado de afinidad potencialmente con un personaje con los brazos extendidos que desconocemos con exactitud sobre el contexto del mismo, hasta ahora sabemos que el ejemplar proviene de la comunidad Kirwas en los raudales del río Coco (arriba) y éste aparece junto al menos cinco a seis motivos reportados por Edward Conzemius (1892-1931), en su libro Estudio Etnográfico sobre los Miskitos y Sumos de Honduras y Nicaragua, que de acuerdo a 
las anotaciones del etnólogo y lingüista luxemburgués exterioriza que sobre las rocas que ocupan el lecho de casi todos los grandes ríos se pueden observar pictografías, especialmente entre raudales y cascadas. Debieron haber sido esculpidas hace muchos siglos, pues se encuentran bastante gastadas por el agua (...), y con respecto a las figuras esculpidas consisten principalmente en representaciones muy curiosas y dificiles de identificar a veces representan figuras humanas, pero en su mayoría ofrecen dibujos animales, jaguares, lagartos, monos, ranas, tortugas y serpientes. Ocasionalmente se observan figuras geométricas, como espirales y volutas, pero los diseños florales están notablemente ausentes (...) y finalmente, desconoce sobre los autores de estas pictografías, lo que sí da por hecho es que tanto Miskitus y Sumus declaran unánimemente que dicho trabajo es el producto de los malos espíritus (Walasa), en tiempos cuando las rocas estaban todavía “suaves", (Conzemius, 2004, p.203105).

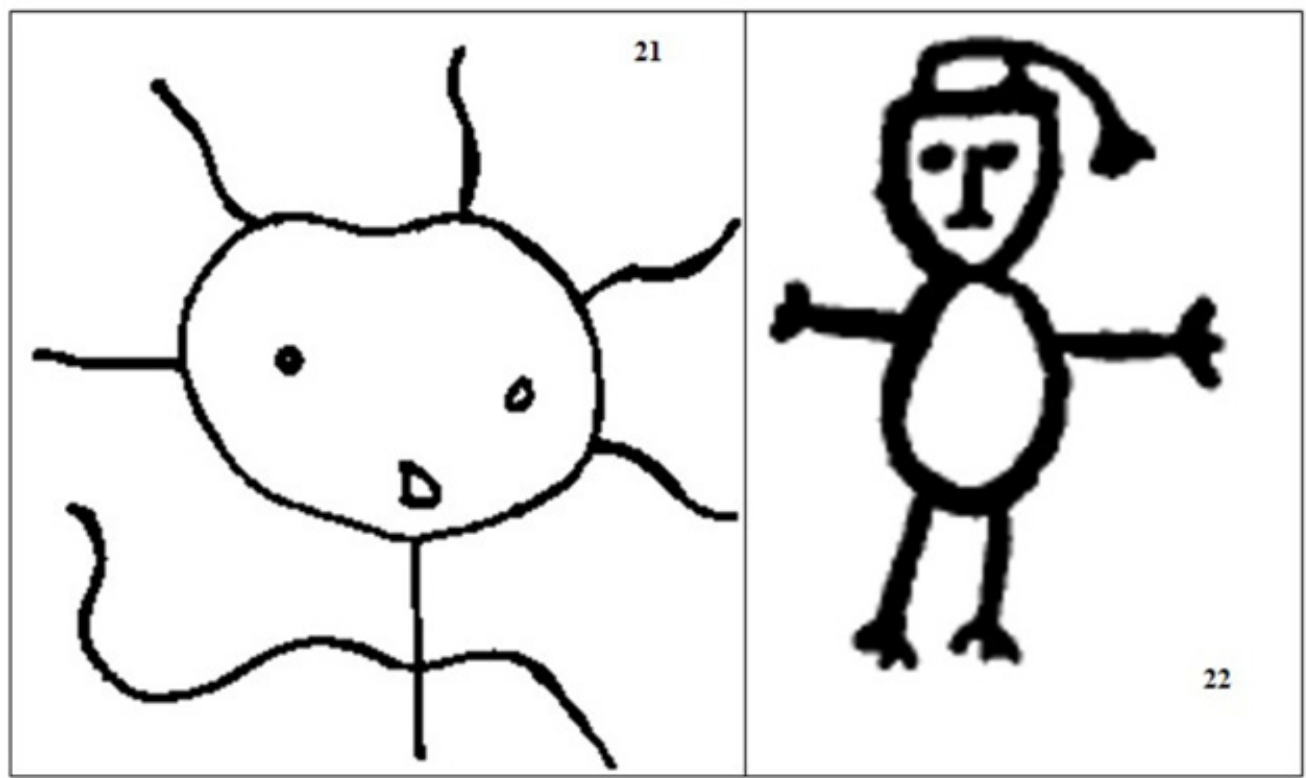

Motivo con característica antropomorfa y elementos vinculados al sol; grabado con detalles antropomorfos de brazos extendidos procedente de Kirwas, río Coco, en la RACCN. Fuente: González y Taylor, 2009.

Ese simbolismo y lenguaje que recoge el autor en su vivencia por la zona quizás puede entenderse en palabras sencillas cuando Edward Taylor (1801-1868) citado por (Sperber,1988:22), señala que "el hombre primitivo, reflexionando sobre la experiencia del sueño, habría inferido de ella la noción de una entidad inmaterial, el "alma", y la habría atribuido enseguida a otros seres, a animales y aun a objetos inanimados, para prestarle en fin una existencia independiente de todo soporte material, bajo la forma de "espíritus".

Hechas las consideraciones anteriores y en la búsqueda por definir los significantes de las dos expresiones de arte en piedra (petrograbados y pictografías) hemos constado la singularidad del motivo concéntrico en otras regiones circundantes a Nicaragua, (además, de la comunidad Kirwas también, hay otro ejemplar similar en la comunidad de Santa Fe, que eventualmente, la simbología parece tener siempre una conexión mitológica con la estrella "Venus" esto por las 
características morfológicas que tiene una especie de cosmograma ${ }^{14}$ (representación de los cuatro rumbos y el centro figurado por el símbolo cruz), siendo de esta forma el arte rupestre una forma de escritura, comunicación y arte (Acuña, 2018, p.2).
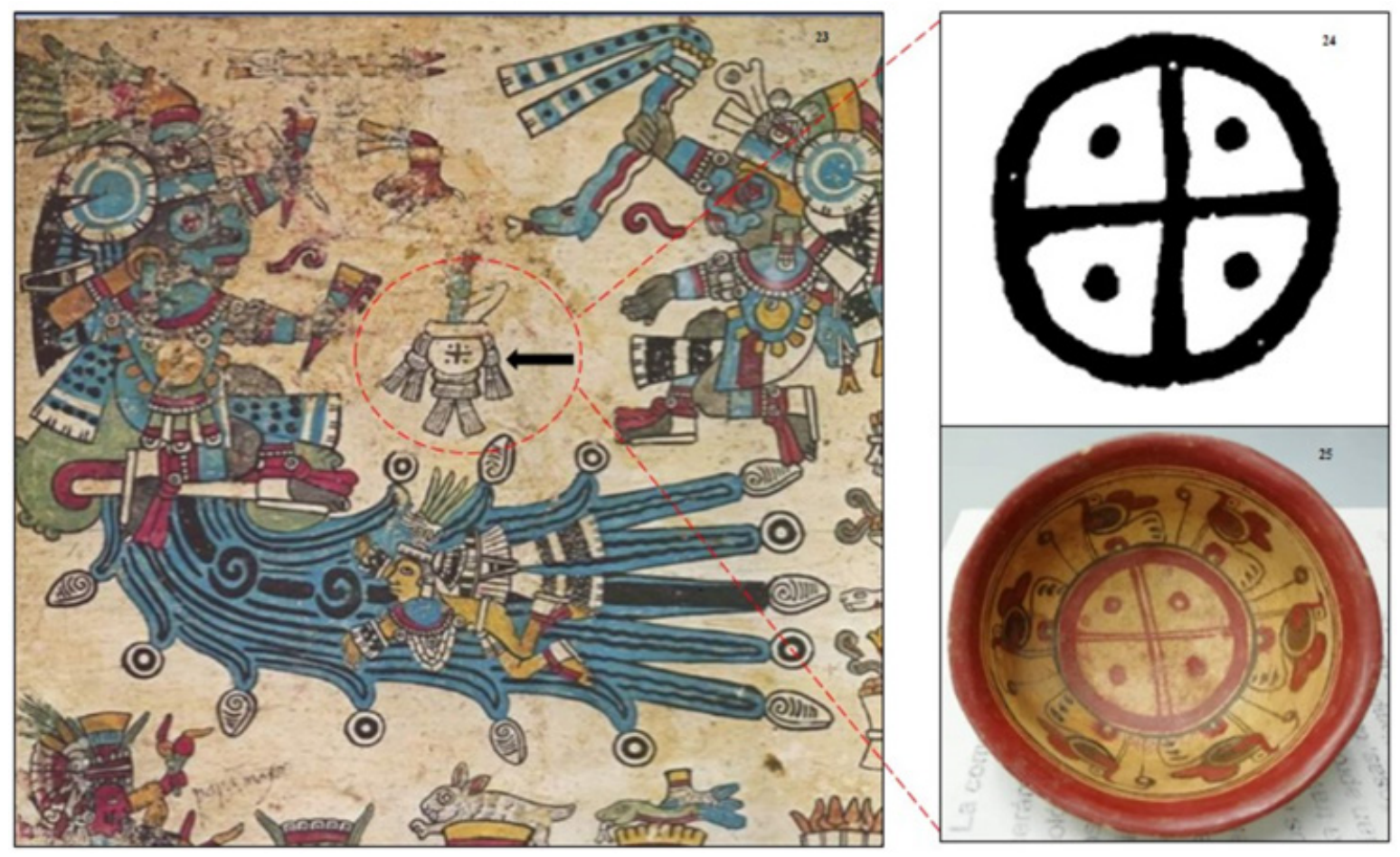

Conexión mitológica con la estrella Venus; en el orden Calendario Mexica, petroglifo en los raudales del río Coco por Edward Conzemius, en su libro "Estudio Etnográfico sobre los Indios Miskitos y Sumus de Honduras y Nicaragua" y cerámica polícromo Copador (600-900 d.C.), documentado en contextos arqueológicos de El Salvador. Fuente: Arqueología Mexicana/Hugo Iván Chávez.

El signo ha sido identificado desde México hasta Argentina, por ejemplo aparece en el calendario Mexica o en el caso de la cerámica polícromo Copador (600-900 d.C.), de El Salvador, por lo que parece ser que este símbolo tuvo implícitas connotaciones simbólicas varias y tuvo presencia en buena parte de América de acuerdo a lo sugerido por el arqueólogo salvadoreño Hugo Iván Chávez (comunicación personal), de hecho los Maya identificaron a Venus con un símbolo específico, el cual se halla repetidas veces en el Código de Dresde y en algunas referencias de Madrid, Paris, Borgia (Sánchez, 2008, p.2).

\section{Esquematización del cuerpo humano y el tema zoomorfo}

El grupo y subgrupo de representaciones antropomorfas es caracterizado por un buen número de rostros y cuerpos enteros, es decir, esquematización del cuerpo humano con características específicas (cabeza, ojos, nariz, boca, extremidades superiores e inferiores) como en el caso de las imágenes 1, 2, 3, 4, 5, 22 y 23. 


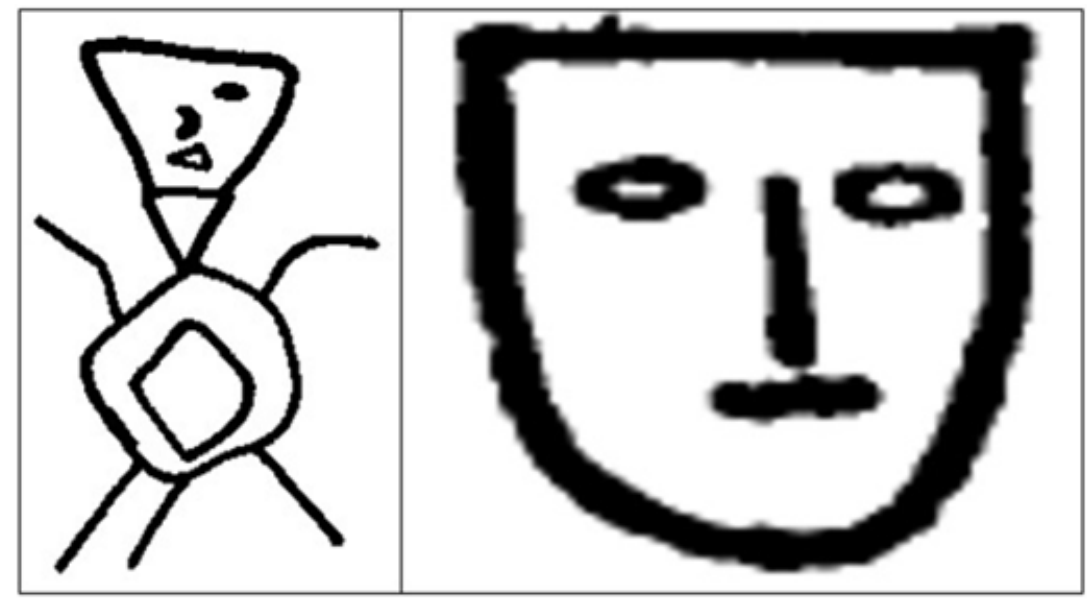

Petrograbado con característica de oficiante, rostro humano con morfología geométrica y en movimiento y grabado documentado en los raudales del río Coco por Edward Conzemius, 1984:104 en su libro "Estudio Etnográfico sobre los Indios Miskitos y Sumus de Honduras y Nicaragua”. Fuente: González y Taylor, 2009.

En particular, el motivo 26 morfológicamente tiene un triángulo que define la cabeza y una línea recta que empieza en la parte inferior de dicha geometría que se extiende hacia abajo en orientación vertical que definen por una parte, brazos en la parte superior del motivo y en su parte inferior pies con círculo concéntrico en el centro o estómago, al igual que la imagen 23 descrito con atuendo (gorro) que porta la figura humana y compuesto por un triángulo que define la cabeza y una circunferencia que determina una especie de estómago abultado al igual que dos líneas rectas en los extremos que hacen entender que el personaje está con los brazos abiertos y otras 2 líneas verticales que definen brazos y pies que pueden interpretarse hipotéticamente como una especie de oficiantes o "propietarios de facultades especiales" (Rizo, 1993, p.38), esto por el atuendo que porta uno de ellos que apunta a un acceso diferencial a ciertos tipos de bienes y por otro lado simboliza la figura humana de diversas formas que en todo caso:

(...) un objeto que está mediado por una figura se convierte desde luego en representación. Por lo tanto, la representación está íntimamente relacionada con el referente del objeto. Dichos objetos dentro de un contexto cultural hacen referencia a un tipo de conocimiento que se relaciona con lo que los sujetos piensan y en el cómo organizan su vida. (Villar y Ramírez, 2014: 54)

Otro de los motivos atrayentes es la imagen 4 que está vinculado a la mitología o deidad del dios de la lluvia, que se dispone por una especie de cuadrado que define la cabeza y donde en el interior de éste se logra apreciar 2 puntos y círculos que precisan ojos que a su vez están determinados por 2 líneas sinuosas que admiten una especie de lágrima y luego una línea vertical que define nariz y un cuadrado que precisa la boca, refiriendo el diseño.

La imagen 27 tiene afinidad con una especie de máscara en referencia al rostro humano determinado por 2 círculos vacíos que define ojos, 1 línea vertical que precisa nariz y otra línea horizontal que orienta la posición de la boca. Sobre el uso de representación gráfica en piedra, se 
practica desde entonces "en todos los pueblos existe la preocupación mimética por disfrazar emociones, exaltarlas, desfigurarlas o inventarlas" (Matillo, 1981, p.14).

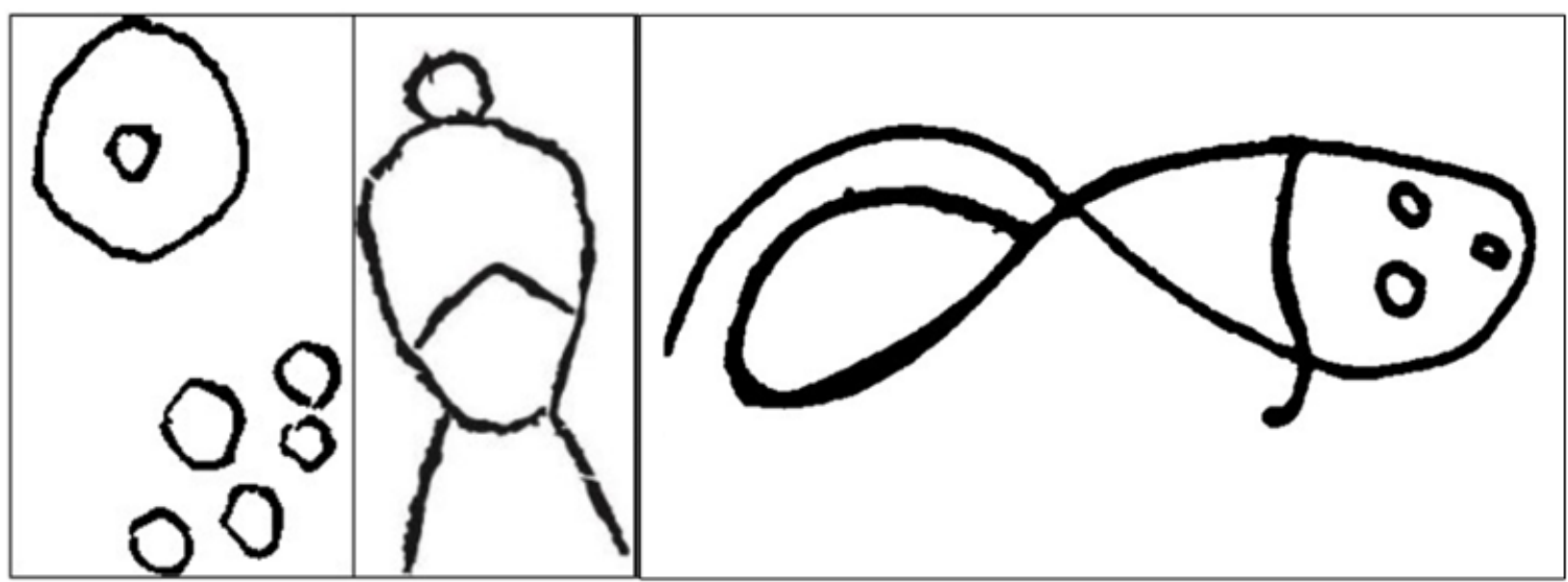

Dibujos de motivos que reflejan elementos zoomorfos entre ellos pisada de felino, silueta de tortuga y un elemento vinculado a un pez. Fuente: González y Taylor, 2009.

Los elementos figurativos zoomorfos se caracterizan por evocar o contemplar escenas propias de la naturaleza en particular su fauna es decir, el análisis recoge un inventario de la fauna local definidos a partir de su estructura morfológica entre ellos una silueta de mono estilizado y determinado por tener una forma de " $V$ " (imagen 6), que hace entrever la forma de cejas y por otros 2 elementos circulares o concéntricas (espirales) de al menos 2 vueltas que orientan la boca de la especie sugerida. Otros elementos que caracterizan la fauna local es la identificación de dos especies de felino tanto rostro y extremidades (imagen 8 y 28), al igual que dos figuras acuáticas una perfectamente vinculado a una tortuga (imagen 29), con una circunferencia que determina la estructura principal del motivo y finalmente, un pez (imagen 30), con presencia de elementos geométricos. Por tanto, hasta este punto los paralelismos se basan en, muchos de los casos, en modelos geométricos horizontales que son la base para la representación por una parte de extremidades (manos, pies, patas) y un elemento vertical que determina la estructura principal de los diversos elementos descritos (cabeza-rostro, ojos, boca).

\section{Consideraciones preliminares}

Un juicio valorativo sobre los contenidos de los motivos es que evidencian en términos generales dos grandes grupos y subgrupos de atractores visuales, aquellos definidos como realistas/naturalistas y abstractos como diseños frecuentes y dominantes que desde el análisis determinan la línea como el elemento esencial en la configuración de los mismos, es decir, líneas verticales/diagonales/curvas son la base de los elementos (rostros y cuerpos antropomorfos y zoomorfos) en tanto, las líneas horizontales expresan extremidades superiores e inferiores al igual que diseños geométricos varios que de acuerdo a la simbólica antigua los elementos antes descritos como el espiral, los círculos, líneas onduladas o en forma de zigzag refieren directa o indirectamente al agua o lluvia. 
Adicionalmente, la conducta humana de las sociedades antiguas estuvo llena de interacciones con el medio ambiente (el caribe nicaragüense es caracterizado por ser una región ampliamente rica en recursos naturales ríos, cascadas y una variada fauna), que de una u otra manera transformaron para bien o para mal las condiciones de vida de estos, pero también señalar que los diseños elaborados en piedra ya sea tallados o pintados reflejan precisamente esas interacciones con el medio en forma de pensamientos, contemplación, tensiones, vivencias cotidianas o lo que simbólicamente entendemos a través, de un "signo" o REPRESENTAMEN (Peirce, 1974, p.1), aquello que desde los planteamientos teóricos de la arqueología definiríamos como estilos construidos justamente a partir de un contexto histórico determinado y que hoy los entendemos como aquella concreción material ancestral o sencillamente arte rupestre que expresan formas de estar y entender el mundo de aquellas sociedades que elaboraron estas obras de arte en piedra. Finalmente, este es una primera entrega sobre una caracterización inicial del arte rupestre alojado en la Región Autónoma de la Costa Caribe Norte, sabiendo que estos ejemplares no resumen desde luego todo el acervo del arte en piedra del territorio por el contrario es ahora cuando más se debe de investigar en esta materia y fortalecer aún más el tema de la identidad local.

\section{AGRADECIMIENTOS}

A Ana Rosa y Patricia Fagoth, al igual que Giulia Trobbiani del Centro Cultural TININISKA, a la arqueóloga Scarleth Álvarez por los dibujos, a la geógrafa Lisseth Blandón en la elaboración del mapa que se presenta y a los pueblos étnicos Miskitu y Sumu de la RACCN.

\section{LITERATURA CONSULTADA}

Arguedas, G. (1992). La Tradición Oral de los Indígenas Sumos: Características y Temáticas. Revista de Filología y Lingüística XVI. (1):55-96.

Acuña, S. (septiembre de 2018). Arte Rupestre: ¿Escritura, Comunicación o Arte? XIX Coloquio Guatemalteco de Arte Rupestre "Gabriel Morales Castellanos", Nueva Guatemala de la Asunción, Guatemala.

Conzemius, E. (2004). Estudio Etnográfico sobre los Miskitos y Sumos de Honduras y Nicaragua. Colección cultural centroamericana, serie etnológica, $\mathrm{n}^{\mathrm{o}} 2$ $1^{\mathrm{a}}$ ed. Managua, Fundación vida.

Constenla, A. (1990). Introducción al Estudio de las Literaturas Chibchas. Revista de Filología y Lingüística XVI. (1):55-96.

Foucault, M. (1992). Microfísica del Poder. Ediciones de La Piqueta, Barcelona.

González Hodgson K \& Taylor, E. (2012). Inventario de Sitios Arqueológicos en el Municipio de Rosita. Recuperado de https://www.lamjol.info/index.php/ WANI/article/download/884/697 
González Hodgson, K \& Taylor, E. (2009). Arqueología en la RAAN: una aproximación alpasado. Tesis monográfica para optar al grado de licenciado en Historia con Orientación en Arqueología. UNAN-Managua. Recuperado de http:// repositorio.unan.edu.ni/11132/

Grupo Guatemalteco Investigación de Arte Rupestre. (2009). Glosario de Términos Rupestres. Escuela de Historia de la Universidad de San Carlos de Guatemala. Nueva Asunción, Guatemala. Recuperado de https://issuu.com/marcelopbarraza/ docs/glosario_final_2009

Hodder, I. (1994). Interpretación en Arqueología: corrientes actuales. $2^{\mathrm{a}}$ ed. Barcelona: Crítica.

Hodder, I. (1985). "Postprocessual Archaeology", Advances in Archaeological Method and Theory. Pp. 1-26.

Houwald, G. (2003). Mayangna, apuntes sobre la historia de los indígenas Sumus en Centroamérica. Managua: Fundación Vida. 668 pp.

Hurtado, de Mendoza. (2000). Identidad Cultural Mayangna en Nicaragua: Sociedad y Ambiente. Consultores.

Incer, J. (1985). Toponimias Indígenas de Nicaragua. Asociación Libro Libre, San José, Costa Rica. pp 481.

Kolpakova, A. (2009). Símbolos Geométricos en la Cerámica de Izapa, Chiapas. Revista Liminar. Estudios Sociales y Humanísticos Año 7, Vol. VII N². Tuxtla
Gutiérrez, Chiapas, México. ISSN:16658027. Recuperado de http://www.scielo. org.mx/pdf/liminar/v7n2/v7n2a7.pdf

Manzanilla, R. (2018, septiembre). Introducción al Registro del Arte Rupestre. Dirección de Salvamento Arqueológico del Instituto Nacional de Antropología e Historia. Ponencia realizada por el autor en el XIX Coloquio Guatemalteco de Arte Rupestre "Gabriel Morales Castellanos", Nueva Guatemala de la Asunción, Guatemala.

Manzanilla, R. (2006). Los Petrograbados de Palma Sola, México: una reinterpretación. En Volumen I Coloquio de Arte Rupestre (Editado por C. Martínez). Pp. 121-131. Publicación Especial, recopilación de los Coloquios guatemaltecos de Arte Rupestre. Edición Digital.

Matillo, V. (1981). Trilogía Arqueológica Rupestre. Máscaras, Magos y Hechiceros, Danzas y Danzantes en el Arte Rupestre de Nicaragua. Tricentenario de la Obra de la Salle en el Mundo: Managua.

Panofsky, E. (1979). El Significado en las Artes Visuales. $4^{\mathrm{a}}$ reimpresión. Alianza Editorial.

Peirce, C. (1974). Clasificación de los Signos. En la Ciencia de la Semiótica. Nueva Visión, Buenos Aires. Recuperado de http://www.inpi.edu.ar/wp-content/ uploads/2017/03/Clasificacion_de_los_ signos-Pierce.pdf 
Rizo, M. (1993). Mito y Tradición Oral entre los Sumus del río Bambana. Revista WANI $N^{\circ} 14$.

Sánchez, D. (2008). El Símbolo de Venus en el Arte Rupestre de Perú, Chile y Norte de Argentina. Fundación de Estudios Indigenistas (FUNDESIN). Recuperado de http://rupestreweb.info/venus2.html

Sperber, D. (1988). El Simbolismo en General. Editorial Anthropos. Barcelona.

Torres, A. (1999). La Observación Astronómica en Mesoamérica. Ciencias 54, abril-junio, 16-27. Recuperado de http://www.revistaciencias.unam.mx/ images/stories/Articles/54/CNS05403. pdf
Troncoso, A. (2003). Proposición de Estilos para elArteRupestredelVallede Putaendo, curso superior del río Aconcagua". Chungará (Arica) [online]. Vol. 35, N². Pp. 209-231. Recuperado de https:// scielo.conicyt.cl/scielo.php?script $=$ sci_ arttext\&pid=S0717-73562003000200003

Villar, M y Ramírez, J. (2014). El Valor Simbólico de la Imagen Representada. Revista Legado de Arquitectura y Diseño. Recuperado de http://www.redalyc.org/ pdf/4779/477947304004.pdf

\section{GLOSARIO}

Antropomorfo: que tiene forma o apariencia humana.

Antropozoomorfo: representación que tiene características humanas y animales.

Arte rupestre: representación de imágenes y símbolos pintados, grabados o incisos sobre superficies rocosas en estado natural, reflejando el paisaje real y sobrenatural del individuo o individuos que lo crearon. Incluye pintura, grabados, geoglifos y arte mobiliar.

Icónico-Iconografía: Signo que está determinado por su objeto dinámico en virtud de su propia naturaleza interna, por ejemplo, una visión, o el sentimiento provocado por una pieza de música considerada como representación de lo que el compositor quiso expresar. También un icono puede ser un diagrama (Peirce, 1974, p.1). En este caso el propósito de la iconografía es identificar, clasificar y explicar las representaciones y objetos rupestres en este caso.

Pictografía: del latín pictum, relativo a pintar, y del griego grapho, relativo a trazar, en pocas palabras son grafismos realizados sobre las rocas mediante la aplicación de pigmentos minerales (carbón, arcillas), animales (sangre, huesos, grasas), o vegetales (grasas, colorantes). 
Representaciones gráficas: si vemos las creaciones rupestres con la mirada desde las artes visuales encontramos un lenguaje visual simbólico, es decir, constituyen un sistema de lenguaje gráfico resultado de actividades humanas que han sido grabadas o pintadas sobre superficies rocosas.

Talla: Desgajamiento de fragmentos de un bloque de roca madre, mediante una fuerza, por percusión o por presión; diseño cortado sobre una superficie con la ayuda de un instrumento afilado.

Zoomorfo: que tiene forma o apariencia animal. 